\title{
Research the sulfonation mechanism of urea in oleum by density functional theory calculation
}

\author{
(C) Andrey A. Degtyarev, ${ }^{*+}$ and Alexandra V. Trishina \\ Department of Chemistry and Chemical Technologies. Tambov State Technical University. \\ Soviet St., 106. Tambov, 392000. Russia. Phone: +7 (4752) 63-44-44. \\ E-mail:ad.dycost@gmail.com,koroleva_tambov@mail.ru
}

\begin{abstract}
*Supervising author; ${ }^{+}$Corresponding author
Keywords: sulfonation, mechanism of reaction, activation energy, DFT, COSMO, oleum, urea, sulfamic acid.
\end{abstract}

Abstract
The work investigates the sulfonation mechanism of urea in oleum, which is used in the synthesis of sulfamic acid. In addition to sulfamic acid, carbon dioxide is also released in the process. The method of density functional theory was used to model the sulfonation reaction using cation $\mathrm{HSO}_{3}{ }^{+}$as a true sulfonating agent.

All elementary acts, intermediates, and transition states of the reaction are determined. Six possible complexes of urea and cation $\mathrm{HSO}_{3}{ }^{+}$are identified, of which two are reactive, formed through the bonding of the nitrogen atom of urea and sulfur of the $\mathrm{HSO}_{3}{ }^{+}$. The most stable complex is formed through the bonding of the oxygen atom of urea and sulfur of the $\mathrm{HSO}_{3}{ }^{+}$, from the reactive complexes it is separated by an activation barrier of $149.86 \mathrm{~kJ} / \mathrm{mol}$, so its formation inactivates the starting reagents and their return to a reactive state is possible only through interaction with negatively charged particles.

The activation energies and thermal effects of the stages are calculated. The first stable intermediate of the process is isocyanic acid. Subsequently, isocyanic acid reacts with sulfuric by two mechanisms: the formation of urethane-like structures of $\mathrm{NH}_{2} \mathrm{COOSO}_{3} \mathrm{H}$ or carbamic acid. The second mechanism is preferred since it requires much milder conditions.

Using the continuum models D-PCM and COSMO, the influence of the solvent on the reaction mechanism was studied. As a solvent, $100 \%$ sulfuric acid was taken.

The maximum activation energy of elementary stages according to the first mechanism was: 167.37 (COSMO) $\mathrm{kJ} / \mathrm{mol}, 169.77$ (D-PCM), without solvent $180.38 \mathrm{~kJ} / \mathrm{mol}$. By the second mechanism: 57.38 $(\mathrm{COSMO}) \mathrm{kJ} / \mathrm{mol}, 59.91$ (D-PCM), without solvent $91.15 \mathrm{~kJ} / \mathrm{mol}$. The number of elementary acts is 6 for the first mechanism and 7 for the second.

\section{References}

[1] L. Shiri, H. Narimani, M. Kazemi. Sulfamic acid immobilized on amino-functionalized magnetic nanoparticles: A new and active magnetically recoverable catalyst for the synthesis of N-heterocyclic compounds. Applied Organometallic Chemistry. 2017. Vol.32. No.1. P.e3927. DOI: 10.1002/aoc.3927.

[2] V.A. Levdansky, A.S. Kondracenko, A.V. Levdansky. Sulfation of microcrystalline cellulose with sulfamic acid in N,N-dimethylformamide and diglyme. J Sib Fed Univ Chem. 2014. Vol.7. No.2. P.162-169.

[3] Y. Chen, Y. Su, F. Jiao, G. Chen. A simple and efficient synthesis protocol for sulfonation of nitrobenzene under solvent-free conditions via a microreactor. RSC Advances. 2012. Vol.2. No.13. P.5637-5644. DOI:10.1039/c2ra20406a

[4] N.V. Orlova, A.G. Yashchenko, A.Yu. Orlov, A.N. Koliukh, D.Yu. Pshichkina. Improvement of crystallisation stage in production of sulfamic acid. Transactions of the Tambov State Technical University. 2014. Vol.20. No.4. P.780-786.

[5] T.I. Okuyama, H. Maskill. Organic Chemistry: A Mechanistic Approach. OUP Oxford. 2013.

[6] H. Cerfontain. Sulfur trioxide sulfonation of aromatic hydrocarbons. Recueil Des Travaux Chimiques Des Pays-Bas. 1985. Vol.104. No.6. P.153-165.

[7] G. Dado, E.A. Knaggs, M.J. Nepras. Sulfonation and Sulfation. In: Kirk-Othmer Encyclopedia of Chemical Technology. New York: Wiley. 2006. DOI: 10.1002/0471238961.1921120611140107.a01.pub2

[8] S. Moors, X. Deraet, G. Van Assche, P. Geerlings, F. De Proft. Aromatic sulfonation with sulfur trioxide: mechanism and kinetic model. Chemical science. 2016. Vol.8. No.1. P. 80-688. DOI:

10.1039/C6SC03500K. 
[9] B. Galabov, D. Nalbantova, von R Schleyer P., H.F. Schaefer. Electrophilic Aromatic Substitution: New Insights into an Old Class of Reactions. Accounts of chemical research. 2016. Vol.49. No.6. P.11911199. DOI: 10.1021/acs.accounts.6b00120.

[10] L.B. Kochetova, T.P. Kustova, D.E. Troitskaya, and Yu.M. Romanova. Kinetics and mechanism of acyl transfer reactions. Part 13. Quantum chemical simulation of mechanisms of the reactions of secondary fatty aromatic amines arensulfonation. Butlerov Communications. 2017. Vol.51. No.9. P.45-56. DOI: 10.37952/ROI-jbc-01/17-51-9-45

[11] L.B. Kochetova and T.P. Kustova. Kinetics and mechanism of acyl transfer reactions. Part 15. Quantumchemicalsimulation of mechanisms of reactions of $N$-ethylaniline sulfonation. Butlerov Communications. 2019. Vol.57. No.2. P.19-27. DOI: 10.37952/ROI-jbc-01/19-57-2-19

[12] C. Lee, W. Yang, R.G. Parr. Development of the Colle-Salvetti correlation-energy formula into a functional of the electron density. Phys. Rev B. 1988. Vol.37. P.785-789.

[13] T.H. Dunning. Gaussian basis sets for use in correlated molecular calculations. I. The atoms boron through neon and hydrogen. J. Chem. Phys. 1989. Vol.90. P.1007-1023. DOI: 10.1063/1.456153

[14] R.A. Kendall, T.H. Dunning, R.J. Harrison. Electron affinities of the first-row atoms revisited. Systematic basis sets and wave functions. J. Chem. Phys. 1992. Vol.96. P.6796-6806. DOI: $10.1063 / 1.462569$

[15] N.B. Balabanov, K.A. Peterson. Systematically convergent basis sets for transition metals. I. Allelectron correlation consistent basis sets for the 3d elements Sc-Zn. J. Chem. Phys. 2005. Vol.123. P.064107. DOI: 10.1063/1.1998907

[16] N.B. Balabanov, K.A. Peterson. Basis set limit electronic excitation energies, ionization potentials, and electron affinities for the $3 \mathrm{~d}$ transition metal atoms: Coupled cluster and multireference methods. $J$. Chem. Phys. 2006. Vol.125. P.074110. DOI: 10.1063/1.2335444

[17] R. Cammi, J. Tomasi. Remarks on the use of the apparent surface charges (ASC) methods in solvation problems: Iterative versus matrix-inversion procedures and the renormalization of the apparent charges. J. Comput. Chem. 1995. Vol.16. No.12. P.1449-1458. DOI: $10.1002 /$ jcc.540161202

[18] A. Klamt, G. Schüürmann. COSMO: A New Approach to Dielectric Screening in Solvents with Explicit Expressions for the Screening Energy and its Gradient J. Chem. Soc. Perkin Trans. 1993. Vol.2. P.799805. DOI:10.1039/P29930000799

[19] R.A. Pierotti. A scaled particle theory of aqueous and nonaqueous solutions. Chem. Rev. 1976. Vol.76. P.717-726. DOI: 10.1021/cr60304a002

[20] J. Langlet, P. Claverie, J. Caillet, A. Pullman. Improvements of the continuum model. 1. Application to the calculation of the vaporization thermodynamic quantities of nonassociated liquids. J. Phys. Chem. 1998. Vol.92. No.6. P.1617-1634. DOI: 10.1021/j100317a048

[21] C. Amovilli, B. Mennucci. Self-consistent-field calculation of Pauli repulsion and dispersion contributions to the solvation free energy in the polarizable continuum model. Journal of Physical Chemistry B. 1997. Vol.101. No.6. P.1051-1057. DOI: 10.1021/jp9621991

[22] M. Liller. Reaction Mechanisms in Sulphuric Acid and other Strong Acid Solutions. San Diego: Academic Press inc. 1971.

[23] A. Klamt, F. Eckert, W. Arlt. COSMO-RS: An Alternative to Simulation for Calculating Thermodynamic Properties of Liquid Mixtures. Annual review of chemical and biomolecular engineering. 2010. Vol.1. No.1. P.101-122. DOI: 10.1146/annurev-chembioeng-073009-100903

[24] K.B. Snow, T.F. Thomas. Mass spectrum, ionization potential, and appearance potentials for fragment ions of sulfuric acid vapor. Int. J. Mass Spectrom. Ion Processes. 1990. Vol.96. No.1. P.49-68.

[25] C.E.L. Myhre, C.J. Nielsen, O.W. Saastad. Density and surface tension of aqueous $\mathrm{H}_{2} \mathrm{SO}_{4}$ at low temperatures. J. Chem. Eng. Data. 1998. Vol.43. P.617-622. DOI: 10.1021/je980013g

[26] L. Oca, J.M. Campillo Robles, M. Bou-Ali. Review and Analysis of Thermophysical Properties of a Sulfuric Acid-Water Electrolyte. Journal of Chemical \& Engineering Data. 2018. Vol.63. No.9. P.3572-3583. DOI: 10.1021/acs.jced.8b00466

[27] C.L. Yaws. Thermophysical Properties of Chemicals and Hydrocarbons. Gulf Professional Publishing. 2014.

[28] A.A. Granovsky. Firefly version 8, www http://classic.chem.msu.su/gran/firefly/index.html

[29] B.M. Bode, M.S. Gordon. MacMolPlt: a graphical user interface for GAMESS. J. Mol. Graphics Mod. 1998. Vol.16. No.3. P.133-138. DOI: 10.1016/S1093-3263(99)00002-9

[30] S.F. Boys, F. Bernardi. The calculation of small molecular interactions by the differences of separate total energies. Some procedures with reduced errors. Mol. Phys. 1970. Vol.19. No.4. P.553-556. DOI: $10.1080 / 00268970110088901$ 